\title{
Rapid differentiation of Francisella species and subspecies by fluorescent in situ hybridization targeting the $23 \mathrm{~S}$ rRNA
}

\author{
Wolf D Splettstoesser ${ }^{1 *}$, Erik Seibold ${ }^{1}$, Ella Zeman ${ }^{1}$, Karlheinz Trebesius ${ }^{2}$, Andreas Podbielski $^{3}$
}

\begin{abstract}
Background: Francisella (F.) tularensis is the causative agent of tularemia. Due to its low infectious dose, ease of dissemination and high case fatality rate, F. tularensis was the subject in diverse biological weapons programs and is among the top six agents with high potential if misused in bioterrorism. Microbiological diagnosis is cumbersome and time-consuming. Methods for the direct detection of the pathogen (immunofluorescence, PCR) have been developed but are restricted to reference laboratories.

Results: The complete $23 S$ rRNA genes of representative strains of $F$. philomiragia and all subspecies of $F$. tularensis were sequenced. Single nucleotide polymorphisms on species and subspecies level were confirmed by partial amplification and sequencing of 24 additional strains. Fluorescent In Situ Hybridization (FISH) assays were established using species- and subspecies-specific probes.

Different FISH protocols allowed the positive identification of all 4 F. philomiragia strains, and more than $40 \mathrm{~F}$. tularensis strains tested. By combination of different probes, it was possible to differentiate the $F$. tularensis subspecies holarctica, tularensis, mediasiatica and novicida. No cross reactivity with strains of 71 clinically relevant bacterial species was observed. FISH was also successfully applied to detect different $F$. tularensis strains in infected cells or tissue samples. In blood culture systems spiked with $F$. tularensis, bacterial cells of different subspecies could be separated within single samples.
\end{abstract}

Conclusion: We could show that FISH targeting the $23 \mathrm{~S}$ rRNA gene is a rapid and versatile method for the identification and differentiation of $F$. tularensis isolates from both laboratory cultures and clinical samples.

\section{Background}

Tularemia is a zoonotic disease caused by the highly infectious, virulent, gram-negative bacterium $F$. tularensis. This bacterial disease occurs in various clinical forms depending on the route of inoculation and the virulence of the $F$. tularensis strain involved [1]. The geographical distribution of $F$. tularensis was long regarded to be restricted to the Northern Hemisphere [2], and only very recently $F$. tularensis-like strains have been cultured in Queensland, Australia [3], and Thailand, South-East Asia [4]. F. tularensis has a broad host range and can affect more animal species than any other zoonotic pathogen [2]. Whereas human infections in North America are mainly due to tick bites or contact

\footnotetext{
* Correspondence: wolfsplettstoesser@bundeswehr.org

${ }^{1}$ Bundeswehr Institute of Microbiology, German Reference Laboratory for Tularemia, Neuherbergstr 11, 80937 Munich, Germany
}

with rabbits, several enzootic cycles have been described in the Eurasia. Here, F. tularensis is often associated with water and aquatic fauna and its transmission is considered to be more complex involving blood-sucking arthropods like mosquitoes or ticks or direct contact with infected mammals $[5,6]$.

Due to its infectious nature, ease of dissemination and high case fatality rate especially in respiratory infection, F. tularensis was the subject in diverse military biological weapons programs and is still included among the top six agents with high potential to be misused in bioterrorism [7].

The taxonomic position of $F$. tularensis is complex and has changed frequently. At present, the Francisellacae family contains four validly published species: $F$. tularensis, F. novicida, F. noatunensis and F. philomiragia. F. philomiragia is an opportunistic pathogen which

\section{Ciomed Central}


has been rarely isolated from immuno-compromised individuals [8]. F. noatunensis has been described to cause a granulomateous disease in fish $[9,10]$. F. novicida was shown to be very closely related to F. tularensis, and most scientific authors consider it to be the fourth subspecies (subsp.) of F. tularensis (F. tularensis subsp. novicida) $[5,11]$. In this paper we will follow this latter nomenclature. Very recently, two further Francisella species have been described [10,11]. Although the four subspecies of $F$. tularensis show close genetic and phenotypic relationship and have probably evolved from a common ancestor, they exhibit striking variation in virulence in humans and animals [1]. Only two subspecies cause the vast majority of clinical tularemia in mammals: F. tularensis subsp. tularensis (Type A), endemic in North America and F. tularensis subsp. holarctia (Type B) which is found in many countries of the holarctic region [5]. Both subspecies show different patterns in mortality and virulence in humans [12]. Type A isolates can cause a life-threatening infection whereas the less virulent type $B$ isolates generally produce a milder disease. Strains of the subspecies tularensis can be further divided into two major clades, AI and AII, which seem to differ in virulence and to cause significant mortality differences in human infections [5,12]. In addition to the well known virulent strains classified into the subspecies described above, there are several lines of evidence showing that the genus Francisella may comprise additional, hitherto unknown species [13-15]. While some strains of Francisella-like bacteria had been grown from immuno-compromised patients $[15,16]$, some putative Francisella species have been identified only by molecular means analyzing specimens from rodents, soil and water samples [13,15]. Moreover, similar uncultivable Francisella-like bacteria have been found in diverse tick species and are believed to represent endosymbionts of arthropods [17].

In clinical microbiology, the established cultivation and serological techniques are not sufficient for the diagnosis of all Francisella species or for a rapid and reliable discrimination of type A or type B tularemia. Cultivation of F. tularensis from clinical specimens requires at least two days; this is followed by detection of specific antigen, e.g. LPS and molecular typing. Some reports have identified unusual $F$. tularensis strains, isolated from patients or rodents, which lack cysteine requirement or production of regular $F$. tularensis LPS $[15,16,18]$. There is accumulating evidence, supported by recent molecular biological analyses, that $F$. tularensis may be difficult to recover in human and animal infection by using standard cultivation techniques, although direct immunofluorescence, immunohistochemical analysis or PCR allows detection of the organism within clinical samples [19-21].
Rapid identification of $F$. tularensis subspecies is important in the monitoring of enzootic tularemia during outbreaks of human tularemia or post-release scenarios [7,22,23].

Thus, rapid and reliable procedures for the direct detection and differentiation of Francisellae in clinical samples may prove helpful to both clinicians and public health authorities. Therefore, a 23S rRNA-based detection approach was developed, since this molecule has been used extensively to elucidate phylogenetic relationships of bacteria at intra- and intergeneric levels and it is also an excellent target for fluorescent in situ hybridization [24-26].

Near full-length 23S rRNA gene sequences for $F$. philomiragia and all four subspecies of $F$. tularensis were determined. Additional sequences for this target, which exists in three copies in the known Francisella genomes, were analyzed by extracting this information from the published whole genomes sequences currently available. These sequence data were used to develop additional primer sets and fluorescently labeled oligonucleotide probes suitable for species- and subspecies-specific fluorescent in situ hybridization (FISH) of pathogenic Francisella species in culture as well as clinical specimens.

\section{Methods}

\section{Preparation of samples for in situ hybridization and PCR}

All bacterial strains used in this study are listed in Table 1 and 2. Francisella strains were grown aerobically on heart cysteine agar ( $\mathrm{HCA}$ ) at $37^{\circ} \mathrm{C}$ and $5 \% \mathrm{CO}_{2}$. All other strains were cultured on Columbia blood agar or in Luria-Bertani (LB) broth (BD, Heidelberg, Germany). Bacterial cells were harvested while in exponential phase, suspended in phosphate buffered saline (PBS), centrifuged, washed in PBS, resuspended in TE buffer (10 mM Tris, $1 \mathrm{mM}$ EDTA [pH8]), and adjusted to an optical density of 1.0 at $600 \mathrm{~nm}$. Bacterial suspensions were prepared for PCR analysis using the QIAGEN (Hilden, Germany) tissue kit as recommended by the manufacturer. For in situ hybridization, harvested cells were processed and fixed with paraformaldehyde (PFA) as previously described [27].

\section{PCR amplification, sequencing of 23S rRNA gene, and single nucleotide polymorphism (SNP) analysis}

Amplification and sequencing with universal primers of one strain of each $F$. tularensis subspecies as well as one strain of the species F. philomiragia were performed as described by Lane [28]. Full length amplification of $23 \mathrm{~S}$ rDNA was obtained by combining primers which bind either to the 3'-end of the $16 \mathrm{~S}$ rRNA gene and or the 5 '-end oft $5 \mathrm{~S}$ rRNA gene with primer sets specific for conserved regions within the $23 \mathrm{~S}$ rDNA 
Table 1 Results of fluorescence in situ hybridization of all Francisella ( $F_{0}$ ) tularensis and $F$. philomiragia strains used in this study.

\begin{tabular}{|c|c|c|c|c|c|c|c|c|}
\hline \multirow[t]{2}{*}{ Species and origin } & \multirow[t]{2}{*}{ Strain } & \multirow[t]{2}{*}{ Alt. designation } & \multicolumn{6}{|c|}{ Hybridization probe } \\
\hline & & & Bwall 1448 & Bwphi 1448 & Bwhol 1151 & Bwnov 168 & Bwtume 168II & Bwmed 1397 \\
\hline \multicolumn{9}{|l|}{ F. tul. subsp. tularensis } \\
\hline Human, Ohio, 1941 & FSC237 & Schu S4 & + & - & - & - & + & - \\
\hline Squirrel, Georgia (USA) & FSC033 & SnMF & + & - & - & - & + & - \\
\hline Tick, BC, Canada, 1935 & FSC041 & Vavenby & + & - & - & - & + & - \\
\hline Canada & FSC042 & Utter & + & - & - & - & + & - \\
\hline Hare Nevada, 1953 & FSC054 & Nevada 14 & + & - & - & - & + & - \\
\hline Human, Utah, 1920 & FSC230 & ATCC 6223 & + & - & - & - & + & - \\
\hline \multicolumn{9}{|l|}{ F. tul. subsp. holarctica } \\
\hline $\begin{array}{l}\text { Live vaccine strain, } \\
\text { Russia }\end{array}$ & F49 & ATCC 29684 & + & - & + & - & - & - \\
\hline Origin unknown & $\mathrm{F} 1$ & BGA & + & - & + & - & - & - \\
\hline Human, Austria, 1997 & F2 & & + & - & + & - & - & - \\
\hline $\begin{array}{l}\text { Human, Austria (Wien), } \\
1997\end{array}$ & F11 & & + & - & + & - & - & - \\
\hline $\begin{array}{l}\text { Hare, Austria, } 1994 \\
\text { (4 isolates) }\end{array}$ & $\begin{array}{l}\text { F6-7, } \\
\text { F54-55 }\end{array}$ & & + & - & + & - & - & - \\
\hline Hare, Austria, 1995 & F8 & & + & - & + & - & - & - \\
\hline Hare, Austria, 1996 & F9 & & + & - & + & - & - & - \\
\hline $\begin{array}{l}\text { Hare, Austria, } 1997 \\
\text { (13 isolates) }\end{array}$ & F12-F24 & & + & - & + & - & - & - \\
\hline $\begin{array}{l}\text { Hare, Austria, } 1998 \\
\text { (2 isolates) }\end{array}$ & F46, F47 & & + & - & + & - & - & - \\
\hline $\begin{array}{l}\text { Macaque, Germany, } 2005 \\
\text { (4 isolates) }\end{array}$ & $\begin{array}{l}\text { F 101, } \\
\text { F107-109 }\end{array}$ & & + & - & + & - & - & - \\
\hline $\begin{array}{l}\text { Water vole, Germany, } \\
2005,(2 \text { isolates) }\end{array}$ & F105-106 & & + & - & + & - & - & - \\
\hline
\end{tabular}

\section{F. tul. subsp. mediasiatica}

\begin{tabular}{lllllll}
\hline Miday gerbil, Kazakhstan, 1965 & F63 & FSC147 & + & - & - & - \\
\hline Tick, Central Asia, 1982 & F64 & FSC148 & + & - & - & - \\
\hline Hare, Central Asia, 1965 & F65 & FSC149 & + & - & - & + \\
\hline
\end{tabular}

\begin{tabular}{|c|c|c|c|c|c|c|c|c|}
\hline \multicolumn{9}{|l|}{ F. tul. subsp. novicida } \\
\hline Water, Utah, 1950 & F48 & ATCC 15482 & + & - & - & + & - & - \\
\hline Human, UK, 2003 & F58 & FSC595 & + & - & - & + & - & - \\
\hline Human, Texas, 1991 & F59 & FSC156 & + & - & - & + & - & - \\
\hline Human, Texas, 1995 & F60 & FSC159 & + & - & - & + & - & - \\
\hline Spain (novicida-like) & F62 & FSC454 & + & - & - & + & - & - \\
\hline \multicolumn{9}{|l|}{ F. philomiragia } \\
\hline Water, Utah & $\mathrm{F} 50$ & ATCC 25016 & $+^{1}$ & + & - & - & - & - \\
\hline Muskrat, Utah, 1959 & F51 & ATCC 25015 & $t^{1}$ & + & - & - & - & - \\
\hline Water, Utah, 1960 & F93 & ATCC 25017 & $t^{1}$ & + & - & - & - & - \\
\hline Water, Utah, 1960 & F94 & ATCC 25018 & $+^{1}$ & + & - & - & - & - \\
\hline
\end{tabular}

Hybridization with specific probes was only performed if prepared cells had shown a positive signal with probe EUB388 (positive control) and no staining with probe NON-EUB388 (negative control).

+: positive signal; - negative signal with 6-FAM or Cy3-labeld probes

$+^{1}$ : Depending on the formamide concentration used for hybridization. For details refer to Results section. $n$ 
Table 2 Non-Francisella organisms from the strain collection of the Bundeswehr Institute of Microbiology tested to assess the specificity of the FISH assay

\begin{tabular}{|c|c|c|c|c|}
\hline Species & Strain designation & EUB388 & NON-EUB338 & Bwall1448 \\
\hline Acinetobacter baumannii & DSMZ 7324 & + & - & - \\
\hline Acinetobacter calcoaceticus & DSMZ 30006 & + & - & - \\
\hline Achromobacter ruhlandii & DSMZ 633 & + & - & - \\
\hline Achromobacter xylosoxidans subsp. denitrificans & DSMZ 30026 & + & - & - \\
\hline Aeromonas hydrophila & ATCC 7966 & + & - & - \\
\hline Alcaligenes faecalis subsp. feacalis & DSMZ 30030 & + & - & - \\
\hline Bacillus cereus & DSMZ 4222 & + & - & - \\
\hline Bacillus mycoides & DSMZ 2048 & + & - & - \\
\hline Bacillus stearothermophilus & DSMZ 5943 & + & - & - \\
\hline Bacillus subtilis & DSMZ 2109 & + & - & - \\
\hline Burkholderia cepacia & B46, clinical isolate (PI) & + & - & - \\
\hline Burkholderia thailandensis & DSMZ 13276 & + & - & - \\
\hline Candida albicans & DSMZ 1386 & + & - & - \\
\hline Citrobacter freundii & DSMZ 30039 & + & - & - \\
\hline Citrobacter koseri & DSMZ 4595 & + & - & - \\
\hline Chromobacterium violaceum & LMG 1267 & + & - & - \\
\hline Clostridium difficile & DSMZ 1296 & + & - & - \\
\hline Eikenella corrodens & DSMZ 8340 & + & - & - \\
\hline Enterobacter aerogenes & DSMZ 12058 & + & - & - \\
\hline Enterobacter cloacae & ATCC 13047 & + & - & - \\
\hline Enterococcus faecalis & DSMZ 2570 & + & - & - \\
\hline Escherichia coli & ATCC 25922 & + & - & - \\
\hline Hämophilus influenzae & DSMZ 4690 & + & - & - \\
\hline Kingella denitrificans & DSMZ 10202 & + & - & - \\
\hline Kingella kingae & DSMZ 7536 & + & - & - \\
\hline Klebsiella pneumoniae & DSMZ 30104 & + & - & - \\
\hline Legionella pneumophila & DSMZ 1296 & + & - & - \\
\hline Listeria monocytogenes & DSMZ 12464 & + & - & - \\
\hline Moraxella catarrhalis & DSMZ 9143 & + & - & - \\
\hline Morganella morganii & DSMZ 6675 & + & - & - \\
\hline Neisseria meningitidis & DSMZ 10036 & + & - & - \\
\hline Ochrobactrum anthropi & DSMZ 7216 & + & - & - \\
\hline Pasteurella multocida & DSMZ 5281 & + & - & - \\
\hline Plesiomonas shigelloides & DSMZ 8224 & + & - & - \\
\hline Propionibacterium acnes & DSMZ 1897 & + & - & - \\
\hline Proteus mirabilis & DSMZ 4479 & + & - & - \\
\hline Proteus vulgaris & DSMZ 30118 & + & - & - \\
\hline Pseudomonas aeruginosa & DSMZ 11810 & + & - & - \\
\hline Pseudomonas putida & DSMZ 291 & + & - & - \\
\hline Pseudomonas stutzeri & NCTC 10450 & + & - & - \\
\hline Psychrobacter phenylpyruvicus & DSMZ 7000 & + & - & - \\
\hline Rahnella aquatilis & DSMZ 4549 & + & - & - \\
\hline Ralstonia pickettii & DSMZ 6297 & + & - & - \\
\hline Salmonella typhimurium & ATCC 13311 & + & - & - \\
\hline Salmonella urbana & $\mathrm{HR}$ & + & - & - \\
\hline Serratia marcescens & DSMZ 30121 & + & - & - \\
\hline Serratia proteomaculans & DSMZ 4543 & + & - & - \\
\hline
\end{tabular}


Table 2: Non-Francisella organisms from the strain collection of the Bundeswehr Institute of Microbiology tested to assess the specificity of the FISH assay (Continued)

\begin{tabular}{|c|c|c|c|c|}
\hline Shigella flexneri & DSMZ 4782 & + & - & - \\
\hline Sphingomonas paucimobilis & DSMZ 1098 & + & - & - \\
\hline Staphylococcus aureus & DSMZ 346 & + & - & - \\
\hline Staphylococcus epidermidis & DSMZ 1798 & + & - & - \\
\hline Staphylococcus hämolyticus & DSMZ 20228 & + & - & - \\
\hline Stenotrophomonas maltophilia & DSMZ 50170 & + & - & - \\
\hline Streptococcus agalactiae & DSMZ 2134 & + & - & - \\
\hline Streptococcus mitis & DSMZ 12643 & + & - & - \\
\hline Streptococcus pneumoniae & DSMZ 20566 & + & - & - \\
\hline Streptococcus pyogenes & DSMZ 20565 & + & - & - \\
\hline Vibrio cholerae & El Tor & + & - & - \\
\hline Vibrio parahaemolyticus & DSMZ 10027 & + & - & - \\
\hline Y. enterocolitica subsp. enterocolitica & ATCC 9610 & + & - & - \\
\hline Yersinia enterocolitica subsp. Palearctica & DSMZ 13030 & + & - & - \\
\hline Yersinia kristensenii & ATCC 33638 & + & - & - \\
\hline Yersinia pestis & EV76 & + & - & - \\
\hline Yersinia pseudotuberculosis & ATCC 29833 & + & - & - \\
\hline Yersinia ruckeri & ATCC 29473 & + & - & - \\
\hline Yersinia frederiksenii & ATCC 33641 & + & - & - \\
\hline Yersinia bercovieri & ATCC 43970 & + & - & - \\
\hline Yersinia rohdei & ATCC 43380 & + & - & - \\
\hline Yersinia mollaretii & ATCC 43969 & + & - & - \\
\hline Yersinia aldovae & ATCC 35236 & + & - & - \\
\hline Yersinia intermedia & ATCC 29909 & + & - & - \\
\hline
\end{tabular}

Abbreviations used in Table 2:

ATCC: American Type Culture Collection; DSMZ: German Type culture collection; HR: General Hospital of Regen; NCTC: National Collection of Type Cultures, London; PI: Pettenkofer Institute for Medical Microbiology, Munich; LMG: Culture collection of the "Laboratorium voor Microbiologie", University Gent

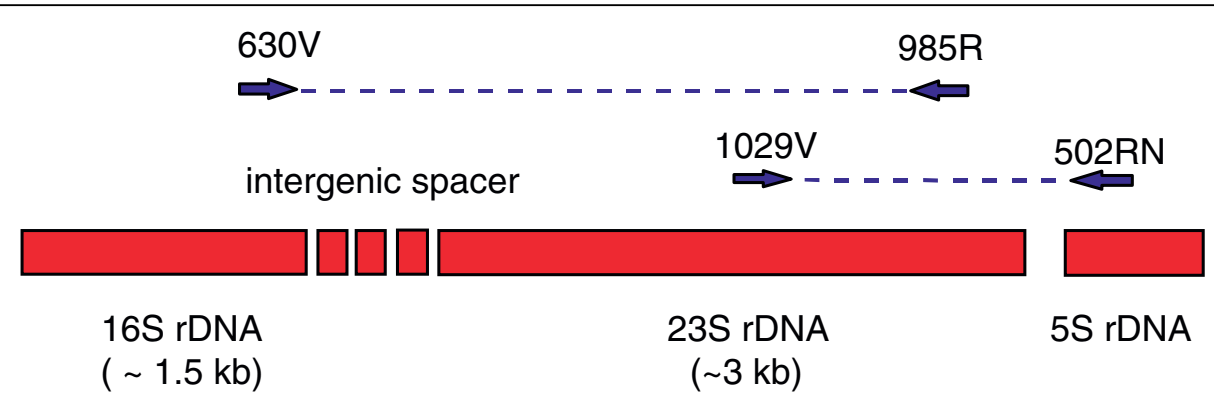

Figure 1 Primer positions for the synthesis of two overlapping 23S rRNA gene fragments covering the complete 23S rRNA gene. Francisella tularensis generally contains three rRNA operons in its entire genome. Analysis of the available whole genomes revealed that theses operons have identical nucleotide sequences.

gene (Fig. 1, Additional file 1, Table S1). PCR reactions with these primer combinations were performed in a Hybaid thermocycler (MWG Biotech, Ebersberg, Germany) resulting in two complementary overlapping amplification products, which were purified (QIAGEN direct purification kit, QIAGEN, Hilden) and checked by gel-electrophoresis. Single-stranded DNAs were sequenced with multiple internal primers (Additional file 1, Table S1) using the LiCor system (MWG Biotech) and ThermoSequenase Cycle Sequencing kits (Amersham, Cleveland, USA). Sequences for both rRNA gene amplificates were determined, quality-checked and aligned. Single nucleotide polymorphisms specific for each subspecies or diverse combination of two subspecies were searched and are summarized in Additional file 1, Table S2. 


\section{Development of PCR primers and hybridization probes} The alignment of all five complete $23 \mathrm{~S}$ rRNA gene sequences and additional six sequences from publicly available whole Francisella genomes were used for the design of new PCR primers and hybridization probes. Primer and probe designations, sequences, positions, and references are listed in Additional file 1, Table S1. Three PCR protocols were developed in order to amplify variable $23 \mathrm{~S}$ rRNA gene regions containing subspecies specific SNPs for 24 additional Francisella isolates comprising strains of each $F$. tularensis subspecies. For each PCR, 2 $\mu \mathrm{L}$ of DNA extracts were used. PCR was performed in a total volume of $50 \mu \mathrm{L}$ containing $20 \mu \mathrm{L} 5$-Prime-MasterMix 2.5× (5 Prime, Hamburg, Germany) and $0.2 \mu \mathrm{M}$ of each the forward and reverse primer. The PCR were performed with a GenAmp PCR System 9700 thermocyler (Applied Biosystems. Foster City, USA). Cycling conditions were: Initial denaturation at $94^{\circ} \mathrm{C}$ for 5 minutes, followed by 30 cycles of denaturation at $94^{\circ} \mathrm{C}$ for 40 seconds, annealing at $56^{\circ} \mathrm{C}$ for 30 seconds and amplification at $72^{\circ} \mathrm{C}$ for 90 seconds and a single final extension at $72^{\circ} \mathrm{C}$ for 5 minutes. The PCR products were purified with the QIAquick PCR Purification Kit ${ }^{\text {tw }}$ according to the manufacturer's manual (Qiagen, Hilden, Germany).

The purified PCR products were sequenced with an BigDye $^{\oplus}$ Terminator v3.1 Cycle Sequencing Kit, Applied Biosystems (Applied Biosystems. Foster City, USA). The total volume of the sequencing reaction-mix was $10 \mu \mathrm{L}$ containing $4 \mu \mathrm{L}$ of the ready mix (BigDye Terminator v3.1 Cycle RR-100) from the kit, $3 \mu \mathrm{L}$ of the purfied PCR product and $0.2 \mu \mathrm{M}$ of the respective sequencing primer. Identical primers were used in both the amplification and sequencing PCR. All sequencing reactions were performed with the same thermocycler as described above. Cycler conditions were: An initial denaturation step at $96^{\circ} \mathrm{C}$ for 1 minute, followed by 25 cycles of denaturation at $96^{\circ} \mathrm{C}$ for 10 seconds, annealing at $50^{\circ} \mathrm{C}$ for 5 seconds, and extension at $60^{\circ} \mathrm{C}$ for $4 \mathrm{~min}-$ utes. The sequencing products were purified with Centri-Sep spin columns (Princeton Separations, Adelphia, USA) and subsequently analyzed on an 3130 Genetic Analyzer (Applied Biosystems. Foster City, USA) in accordance with the instructions of the manufacturer.

Genus-, species- and subspecies-specific oligonucleotide probes for fluorescent insitu hybridization were developed using the software package ARB http://www. arb-home.de and probeBase http://www.microbial-ecology.net/probebase, synthesized and tagged with 6-FAM or Cy3 fluorescence dyes (MWG, Ebersberg, Germany).

\section{Whole-cell in situ hybridization}

In situ hybridization on glass slides was performed as described previously [27]. For the detection or identification of each Francisella species or subspecies, two probe combinations were hybridized simultaneously to the reference cells and to the clinical samples in most cases. While testing the specificity and sensitivity of the newly developed probes, each preparation of reference cells from all different bacterial strains were additionally probed with a generic eubacterial probe (EUB338) and a non-sense nucleotide probe (NonEUB338) to confirm accessibility of the target rRNA as well as to exclude unspecific labelling of bacterial cells or tissue due to preparation artefacts [29]. Probes Bwall1448 and Bwphi1448 were used together to detect all Francisella species and to discriminate between $F$. philomiragia and F. tularensis. The combination of probes Bwtume168II and Bwmed1397 was applied in order to identify and discriminate $F$. tularensis subsp. tularensis (type A) and F. tularensis subsp. mediasiatica. Isolates of the subspecies $F$. tularensis holarctica and $F$. tularensis subsp. novicida were identified using probes Bwhol1151 or Bwnov168, respectively.

The addition of 30,35 or $50 \%$ formamide to the hybridization buffer resulted in specific hybridization of the oligonucleotides to their respective target organisms. To reduce the amount of toxic waste, formamide was not used in the washing steps following hybridization. As a substitute, the $\mathrm{NaCl}$ concentration was decreased in the washing buffer according to the formula of Lathe [30] to obtain the necessary stringency. Citifluor (Citifluor Ltd., London, United Kingdom) was used as a mounting medium on hybridized slides, and the slides were examined both with a Leica (Heerbrugg, Switzerland) TCS NT scanning confocal microscope equipped with a standard filter set and a conventional fluorescence microscope (Axiostar plus/Axio CAM MR, Zeiss, Jena Germany). For probe excitation, an argonkrypton laser (Leica) or a mercurium-spectral light was used. Three different fluorochromes (DAPI, 6-FAM and Cy3) could be detected simultaneously with three different photomultipliers utilizing the green (6-FAM), red (Cy3), and blue (DAPI) channels of the Leica Application Suite (Leica) or Axiovision 4.5 (Zeiss) software packages. For the tissue sections, optical sectioning ( 0.5 to $1.0 \mu \mathrm{m}$ width) was performed to reveal the three-dimensional localization of the probeconferred fluorescence within the samples. The standard software delivered by the manufacturers was used to further process the digitized images.

\section{Identification of different $F$. tularensis subspecies in clinical material and infected cell cultures}

Aerobic BACTEC blood culture bottles (BD, Heidelberg, Germany) were spiked with live bacterial cells from different $F$. tularensis subspecies. Single cultures were started with inoculums of 10 to 1000 colony forming units (cfu) in $5 \mathrm{ml}$ whole human blood. Additionally, cells from two different subspecies were mixed at ratios of $1: 1,1: 10,1: 100,1: 1000$ and then cultured under 
aerobic conditions until the BACTEC instrument reported bacterial growth. Aliquots of 10 to $40 \mu \mathrm{l}$ were dropped onto glass slides, air-dried and then fixed with PFA as described above.

Two different cell lines, the human monocyte/macrophage lineage U937 and the mouse macrophage cell line J 774 were infected with $F$. tularensis subsp. holarctica and F. tularensis subsp. novicida at a multiplicity of infection (MOI) of 100, incubated for 120 minutes and then fixed with paraformaldehyde [31]. Paraffinembedded organs (spleen and liver) samples were sectioned with a microtome, fixed on glass slides, deparaffinized with alcohol and then subjected to the standard fluorescent in situ hybridization protocol.

\section{Nucleotide accession numbers}

The nearly complete $23 S$ rRNA gene sequences of $F$. tularensis subsp. mediasiatica Francisella Strain Collection (FSC) 147, F. tularensis subsp. tularensis Schu S4, F. philomiragia ATCC 25017, F. tularensis subsp. holarctica ATCC 29684, and F. tularensis subsp. novicida ATCC 15482, have been deposited under accession numbers GU073995 to GU073998 and GU073986, respectively.

The partial $23 S$ rRNA gene sequences of 24 additional Francisella strains have been deposited under accession numbers GU073970 to GU073985, and GU073987 to GU073994.

\section{Results}

Sequence analysis of the 23S rRNA gene and phylogeny The PCR primers 630V, 985R, 1029V and 502RN directed the synthesis of two overlapping $23 \mathrm{~S}$ rRNA gene fragments, which covered the complete 23S rRNA gene (Fig. 1). Complete double-stranded sequences of these amplicons were determined for the five strains $F$. tularensis subsp. tularensis Schu S4, F. tularensis subsp. holarctica ATCC 29684, F. tularensis subsp. mediasiatica FSC 147, F. tularensis subsp. novicida ATCC 15482, and F. philomiragia ATCC 25017. The 23S rRNA gene sequences of the $F$. tularensis subspecies exhibited very high levels of homology ( 99.4 to $99.9 \%$ identity). Between F. tularensis subsp. tularensis FSC 237 (Schu S4) and F. tularensis subsp. holarctica (LVS, ATCC 29684) 11 different single nucleotide substitutions were found. Differences between F. tularensis subsp. novicida (ATCC 15482) and the three other subspecies ranged from 10 to 19 single nucleotide substitutions.

We identified regions of intrageneric or intraspecies variability that allowed discriminating between the species F. tularensis and F. philomiragia. In contrast to former results on the corresponding $16 \mathrm{~S}$ rRNA gene sequences [32], the 23S rDNA genes displayed several single nucleotide polymorphisms (SNPs), which allowed a definite discrimination of Francisella strains on the subspecies level and even confirmed the differentiation of type AI and type AII clades (Additional file 1, Table S2).

\section{PCR for confirmation of SNP}

Three variable regions in the $23 \mathrm{~S}$ rDNA genes were also sequenced in 24 additional Francisella strains using specific primers based on results from the initial sequence analysis. Thus, most of the SNPs shown in Additional file 1, Table S2 were confirmed. Only the single nucleotide substitution at position 913 (A versus G) was found to be specific for F. tularensis subsp. tularensis Schu S4 and other AI strains. All type AII strains displayed the Francisella consensus sequence at this position. The phylogenetic tree generated using a neighbor joining analysis procedure (Fig. 2) is consistent with data from the $16 \mathrm{~S}$ rRNA gene and a whole genome SNP phylogeny [5] showing that $F$. philomiragia is clearly distal from the $F$. tularensis subspecies. Among the latter, strains of the subspecies F. tularensis subsp. novicida are distinct and derived from the ancestral lineage leading to the other subspecies. The phylogeny then separates into two lineages with $F$. tularensis subsp. tularensis and F. tularensis subsp. mediasiatica on one side and strains belonging to F. tularensis subsp. holarctica on the other. The type A strains can then be further separated into two groups corresponding to the known subtypes AI and AII.

\section{Sensitivity and specificity of in situ hybridization}

Probe Bwall1448 was targeted to an rRNA region unique for the genus Francisella and gave a positive signal for all Francisella strains tested in this study (Table 1 ). Due to a single mismatch within the binding site of this probe in F. philomiragia strains, the simultaneous application of a second probe (Bwphi1448), labeled with a different fluorochrome allowed the identification of all investigated Francisella strains on the species level by a single analysis (Fig. 3). Alternatively, each probe could be combined with EUB338, a probe targeted to a $16 \mathrm{~S}$ rRNA-sequence conserved in most bacterial species, to rapidly exclude the presence of either $F$. tularensis or $F$. philomiragia in a bacteria-containing sample.

All five available $F$. tularensis subsp. novicida strains hybridized to the probes Bwall1448 as well as the novicida-specific probe Bwnov168 that binds within helix $10 \mathrm{~b}$ of the $23 \mathrm{~S}$ rRNA. Probe Bwhol1151 (binding site nt 1151 to nt 1170 , helix 45 ) is complementary to all $F$. tularensis holarctica sequences and gave strong signals when hybridized to its respective target strains (Table $1)$. No cross reactivity with F. tularensis subsp. tularensis or other subspecies were observed.

The lack of suitable SNPs specific for all F. tularensis subsp. tularensis strains made it necessary to develop a 


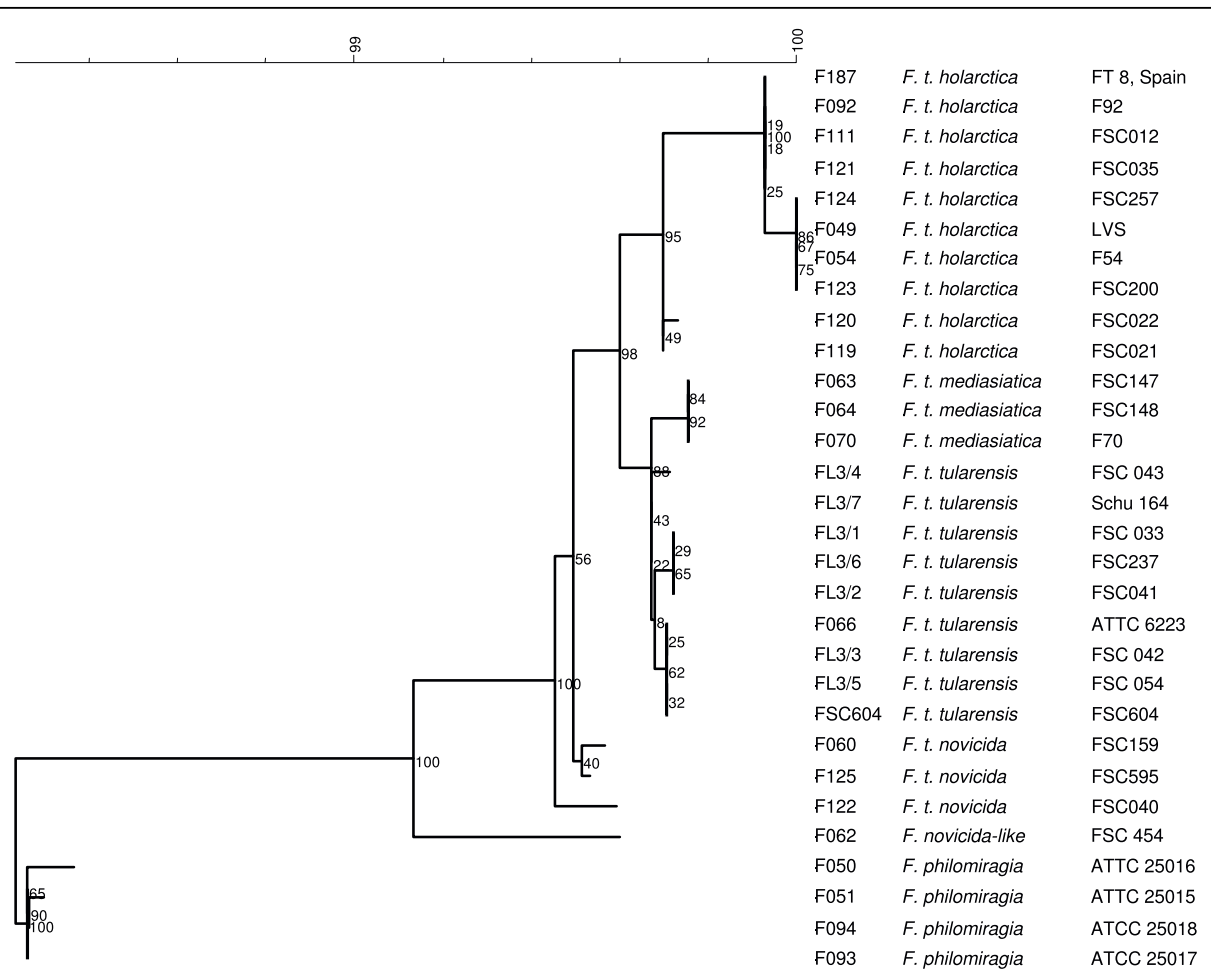

Figure 2 Phylogentic tree based on nearly complete nucleotide sequences of $23 S$ rRNA gene of $F$. tularensis and $F$. philomiragia generated using a neighbor joining analysis. Bootstrap values based on 1000 resamplings are indicated at branch points.
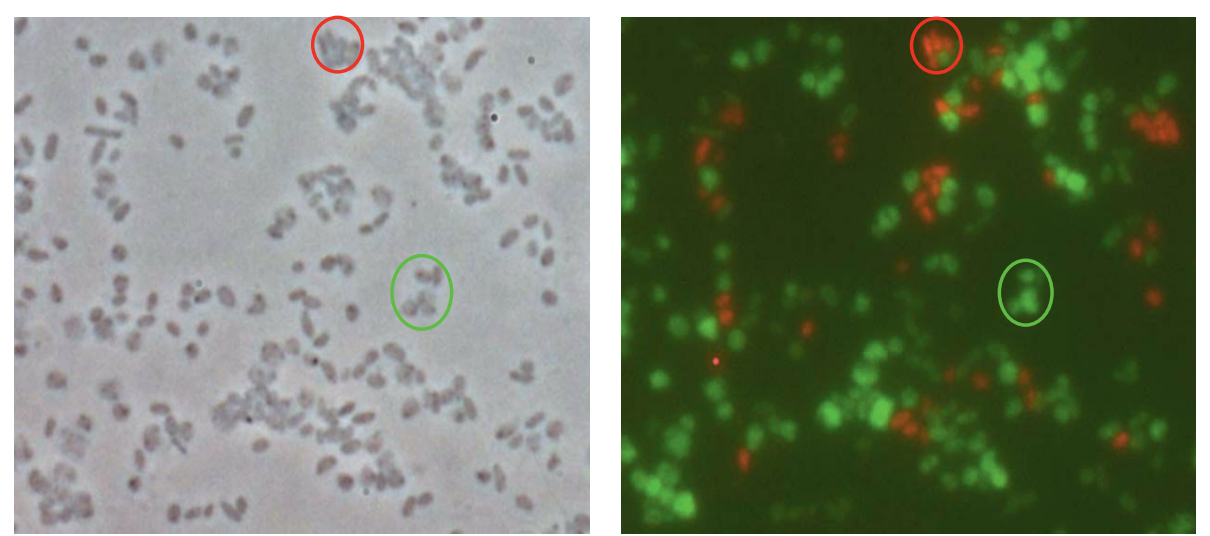

Figure 3 Left: Artificial mixture of $F$. tularensis subsp. tularensis (Schu S4, red circle) and F. philomiragia (ATCC 25017, green circle), phase contrast microscopy. Right: Fluorescence microscopy after hybridization with probes Bwall1448-Cy3 and Bwphi1448-6-FAM with 50\% formamide. The green, pleomorphic cells of $F$. philomiragia can be easily distinguished from the smaller, coccoid rods of the highly virulent $F$. tularensis subsp. tularensis strain showing red fluorescence.

double-staining approach using two probes which are either complementary to all subspecies mediasiatica and tularensis sequences (probe Bwtume168II) or only to the $23 S$ rRNA of $F$. tularensis subsp.mediasiatica (Bwmed1379) (Fig. 4). The first probe was directed to position nt 168 to 184 (helix 10b) which contains two SNPs which prevents its hybridization to sequences of $F$. philomiragia, F. tularensis subsp. novicida and type B strains. The second probe exclusively bound to the RNA of $F$. tularensis subsp. mediaiasiatica strains due to a single SNP located in the center of the probe binding site and discriminating these strains from all other gamma proteobacteria in the $23 \mathrm{~S}$ rRNA database (Table 1). The simultaneous or consecutive application of all probes allows an unambiguous identification of a query isolate to the subspecies level within a few hours (Fig. 5). 

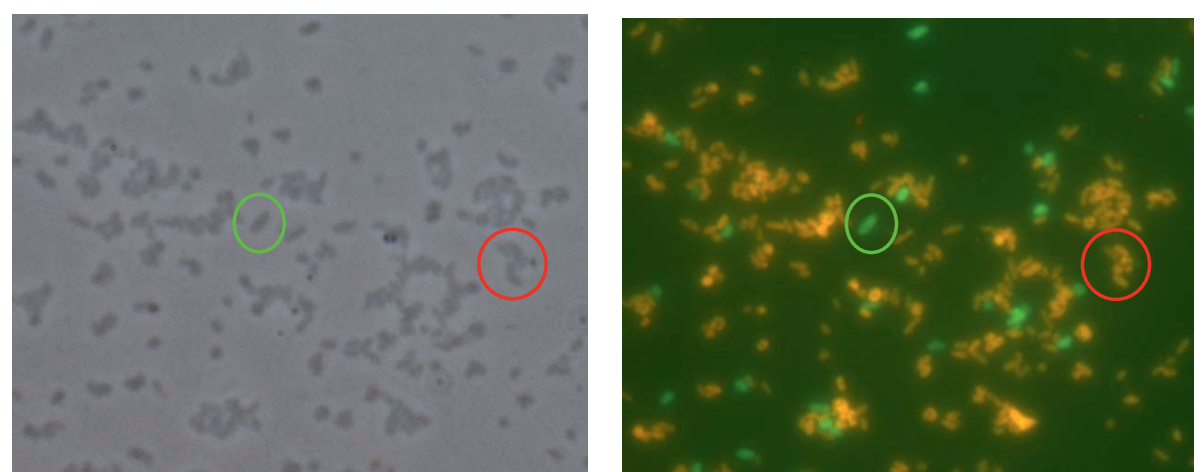

Figure 4 Left: Artificial mixture of $F$. tularensis subsp. tularensis (Schu S4, green circle) and F. tularensis subsp. mediasiatica (FSC 148, red circle), phase contrast microscopy. Right: Fluorescence microscopy after hybridization with probes Bwmed1379-Cy3 and Bwtume1681I-6FAM with $20 \%$ formamide. F. tularensis subsp. tularensis cells only bind to probe Bwtume168ll-6-FAM (green fluorescence) whereas bacterial cells of $F$. tularensis subsp. mediasiatica bind to both probes resulting in a yellow-orange fluorescence.

In situ detection and identification of Francisella bacterial cells in tissue samples, cell-, and blood-culture

Spleen and liver paraffin sections from experimentally or naturally infected mice or non-human primates, were fixed, pre-treated to remove the embedding medium and then hybridized with probes EUB338, non-EUB338, Bwall1448, Bwnov168 and Bwhol1151. All tissue and cell culture samples showed moderate to strong autofluorescence. Despite such interference, the bacterial cells could be detected by using fluorescence microscopy and additional DNA staining with DAPI. In the infected tissue or cell culture samples, F. tularensis subsp. holarctica and F. tularensis subsp. novicida could then be identified by hybridization with their specific probes (Fig. $6+7$ ).

An automated blood culture system (BACTEC, BD, Heidelberg, Germany) was used to grow bacterial cells from each representative strain initially used for $23 \mathrm{~S}$ rRNA gene sequencing. The culture bottles were spiked with $5 \mathrm{ml}$ of human blood and the bacteria grown on HCA medium. Depending on the subspecies and the initial inoculum size, growth in aerobic blood culture bottles occurred between two to eleven days of incubation. Bacterial cells from each subspecies were strongly labeled with their corresponding probes as well as the EUB338 probe used for positive control (Table 3).

In mixed samples containing bacterial cells from different strains (e.g. type A as well as type B) both populations could be easily separated by whole cell hybridization with distinctly labeled probes (Fig. 8). By this approach, for instance, one type A bacterial cell can be detected and unequivocally identified in 1.000 type B cells.

\section{Discussion}

Tularemia is a rare but dangerous zoonosis, which is endemic in almost all countries of the Northern
Hemisphere. In some areas like Central and Southern Europe as well as Turkey, tularemia is an emerging or re-emerging disease representing a significant threat for public health [33-35]. Its causative agent, F. tularensis, is regarded as a potential biological warfare or bioterrorism agent of the highest category. For these reasons clinical and public health laboratories are urged to provide rapid and reliable diagnostic tools for the sensitive detection and identification of $F$. tularensis and for the appropriate differentiation of its subspecies or clades which often display significantly divergent pathogenic potential $[12,22]$.

In contrast to most other bacterial pathogens, cultivation of $F$. tularensis is difficult due to its fastidious nature and its susceptibility to overgrowth by concomitant flora. Additionally, growth may be delayed (up to 12 days) and cultivation of $F$. tularensis poses a significant threat of laboratory infections. Only recently, conventional and real-time PCR protocols for the detection and identification of F. tularensis have been published, but still none of these techniques is sufficiently evaluated to be routinely used in clinical laboratories [36].

In this study we evaluated the potential of rRNA gene targeted PCR and sequencing as well as fluorescent in situ hybridization for the detection and differentiation of Francisella species. In- silico analysis of partial and complete $16 \mathrm{~S}$ rRNA genes available in publicly accessible databases like GenBank confirmed the results of a previous study by showing that $16 \mathrm{~S}$ rRNA sequences from $F$. tularensis subspecies are almost identical, and therefore, are only of limited value for the detection and discrimination of $F$. tularensis on the species or subspecies level [32]. In this regard, the difficulties to discriminate type $A$ and type $B$ strains resembled the situation in the closely related zoonotic pathogens Yersinia (Y.) pseudotuberculosis and Y. pestis or Burkholderia (B.) pseudomallei and B. mallei $[25,37,38]$ 


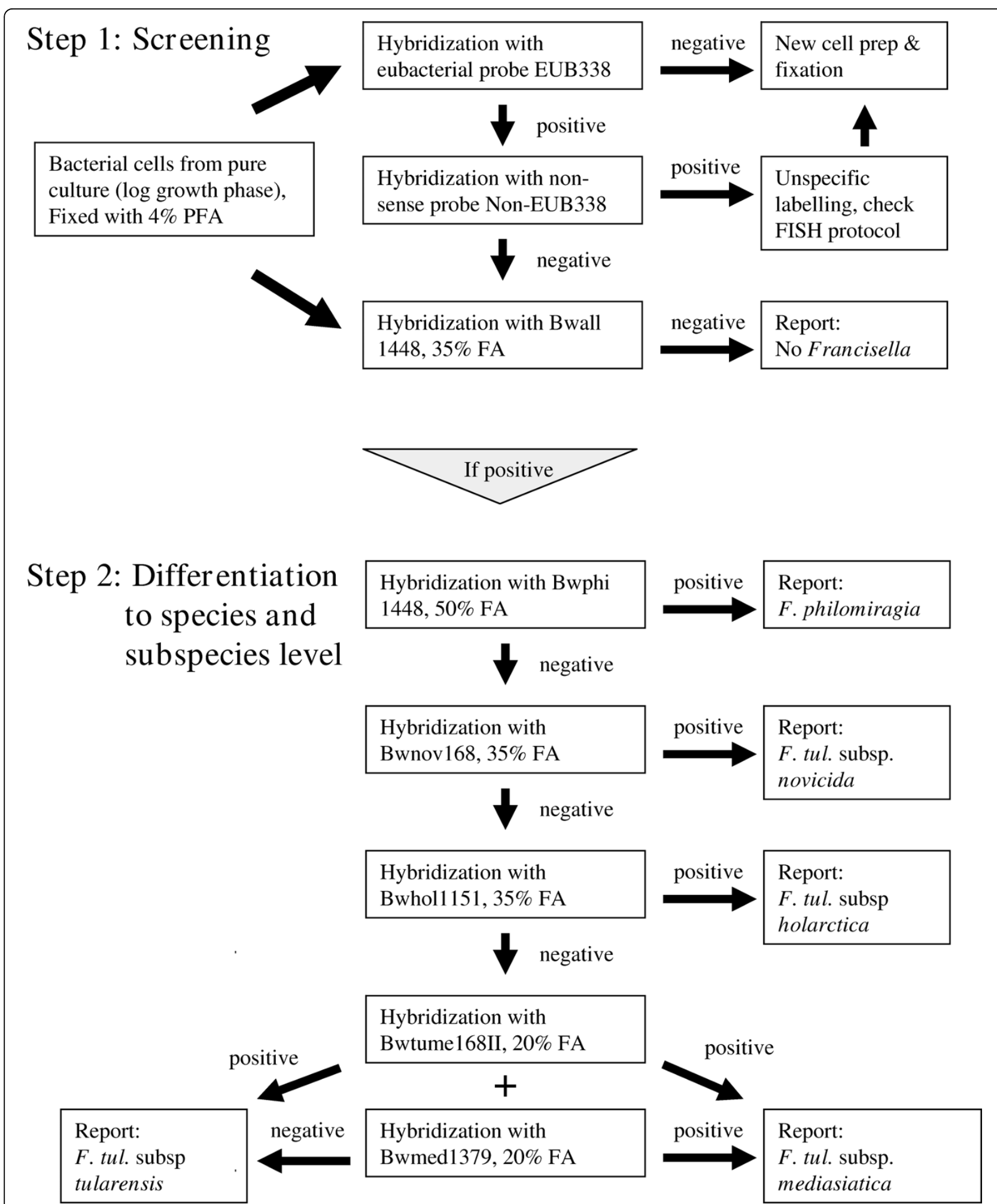

Figure 5 Two-step algorithm for the rapid identification and differentiation of Francisella strains using fluorescence in situ hybridization. After an initial hybridization step with three probes including the "pan-Francisella" probe Bw-all1488, negative samples can directly be reported. Performing internal controls with probe EUB-338 allows recognizing false negative results caused by technical problems. After hybridization with all species- and subspecies-specific probes in parallel, initially positive samples can be further differentiated by following the algorithm depicted in step two allowing unambiguous identification to subspecies level. 

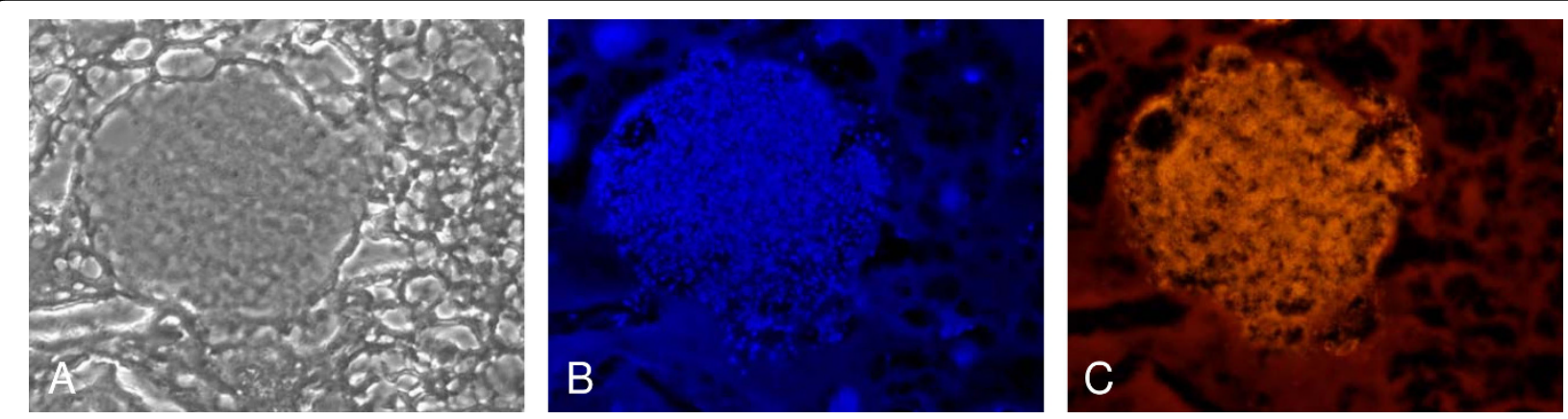

Figure 6 Specific detection of $F$. tularensis subsp. holarctica in a liver tissue sample (mouse) fixed in formalin and embedded in paraffin for more than four years. After deparaffinization and fluorescence in situ hybridization, bacterial cells can be visualized in small granuloma (A: phase contrast microscopy; B: fluorescence microscopy, DAPI staining; C: Specific staining of $F$. tularensis subsp. holarctica).
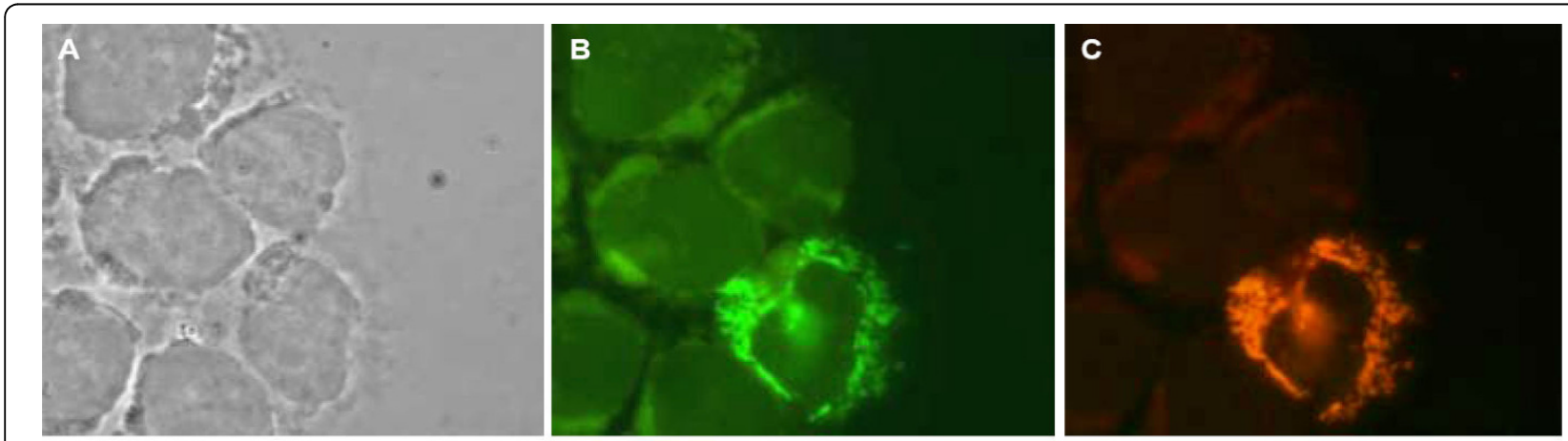

Figure 7 Cytospin preparation of infected $U 937$ cell culture followed by specific detection of the facultative pathogen $F$. tularensis subsp. novicida (MOI 10:1, 24 h). (A: phase contrast microscopy; B: FISH, probe EUB338-6-FAM; C: FISH, probe Bwnov168-Cy3).

Table 3 Identification of different $F$. philomiragia and $F$. tularensis subspp. in positive blood culture using FISH.

\begin{tabular}{|c|c|c|c|c|c|c|}
\hline & $\begin{array}{c}\text { Bwall1448 } \\
\text { (35\% FA) }\end{array}$ & $\begin{array}{c}\text { Bwphi1448 + } \\
\text { Bwall1448 } \\
(50 \% \text { FA })\end{array}$ & $\begin{array}{c}\text { Bwhol1151 + } \\
\text { Bwhol1151 } \\
(35 \% F A)\end{array}$ & $\begin{array}{c}\text { Bwnov168+ } \\
\text { Bwnov168 } \\
(35 \% F A)\end{array}$ & $\begin{array}{c}\text { Bwtume168II + } \\
\text { Bwtume168 } \\
(20 \% \mathrm{FA})\end{array}$ & $\begin{array}{c}\text { Bwmed1379 + } \\
\text { Bwmed1379c } \\
(20 \% \mathrm{FA})\end{array}$ \\
\hline $\begin{array}{l}\text { F. tul. subsp. } \\
\text { holarctica }\end{array}$ & + & - & + & - & - & - \\
\hline $\begin{array}{l}\text { F. tul. subsp. } \\
\text { mediasiatica }\end{array}$ & + & - & - & - & + & + \\
\hline $\begin{array}{l}\text { F. tul. subsp. } \\
\text { novicida }\end{array}$ & + & - & - & + & - & - \\
\hline F. philomiragia & + & + & - & - & - & - \\
\hline
\end{tabular}

Blood culture bottles were inoculated with $5 \mathrm{ml}$ venous blood spiked with $10^{2} \mathrm{CFU}$ of each different strain.

+: positive hybridization

-: negative reaction, no fluorescence

In contrast to those studies, comparison of full-length 23S rRNA genes of all $F$. tularensis subspecies as well as F. philomiragia revealed several discriminative SNPs. The sequence data obtained from rRNA gene sequences, known to be highly conserved in bacterial phylogeny, could be successfully used for the construction of hybridization probes, allowing a rapid genotype-based detection of Francisella species on different taxonomic levels.
A unique 23S rRNA target region suitable for the detection of $F$. tularensis subsp. holarctica (type B) could be identified. For the discrimination of $F$. tularensis subsp. tularensis (type A) and subsp. mediasiatica, an identification approach was developed by employing two different probes. Six type A strains, 31 type B strains as well as three $F$. tularensis subsp. mediasiatica strains were correctly identified by this approach, 


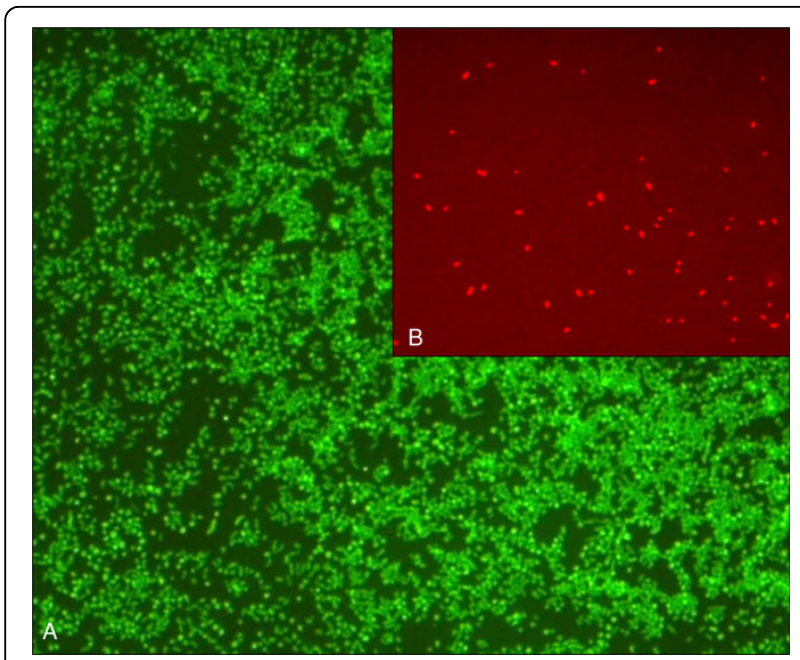

Figure 8 Mixed sample of bacterial cells from $F$. tularensis tularensis (ATCC 6223) and F. tularensis subsp. holarctica LVS (ratio 100:1). Contamination lower than $1 \%$ could be identified using appropriate probe sets. (A: FISH staining with probe EUB3386-FAM for staining of all bacteria in liquid samples. B: Specific staining of F. tularensis subsp. holarctica).

whereas no false-positive signal was observed with 71 other variably related bacterial species.

Similar results were gained employing species-specific probes for F. philomiragia and F. tularensis, which were tested with all mentioned $F$. tularensis strains as well as four $F$. philomiragia strains. We also developed an in situ hybridization protocol for $F$. tularensis subsp. novicida, which allowed the detection of all four available strains of this subspecies. However, due to the possible genetic variability within this subspecies [39] it remains to be elicited if the designed probe will also recognize other so called 'novicida-like' strains [3,4,13-16]. While the final version of this manuscript was written, $23 \mathrm{~S}$ $r R N A$ gene sequences of the aforementioned fish pathogenic members of the genus Francisella became publicly available $[9,10]$. An in silico analysis of these sequences revealed that strains of the species $F$. noatunensis will be probably detected by probe Bwall1448. The available data also indicate, that at it might be possible to discriminate between $F$. noatunensis comp. nov. and $F$. noatunensis subsp. orientalis if probe Bwphi1448 would be combined with probe Bwall1448. It is mandatory to experimentally verify these sequence-based predictions.

Caused by the genetic homogeneity and the clonal population structure of $F$. tularensis, discrimination of bacterial strains to the subspecies level by means of conventional PCR was almost impossible until 2003 [40]. Today, the application of different real-time PCR techniques using fluorescently labeled probes allows the discrimination of type A and type B strains from culture or clinical samples $[20,41,42]$. However, these techniques need sophisticated and expensive instrumentation and none of the published protocols are sufficiently validated to be directly used in routine microbiology.

Fluorescent oligonucleotide probing of whole cells is fast (less than two hours), reliable and could be analyzed by regular fluorescence microscopy, which is available in virtually all clinical or public health laboratories. In tularemia, immunofluorescence staining of clinical samples with anti-F. tularensis LPS antibodies is routinely applied [19], but antibodies discriminating the different subspecies are not available. Fluorescent in situ hybridization could be a rapid, complementary method to confirm preliminary results and to additionally allow the definitive identification of the respective subspecies that caused the infection. This could be important for the clinical patient management with respect to the known differences in type-specific virulence as well as for epidemiological investigations of tularemia outbreaks [23].

For two additional reasons, fluorescent in situ hybridization is a suitable alternative to biochemical identification or PCR. First, it can be applied to thoroughly inactivated clinical or culture samples thereby reducing the threat of laboratory infection. Second, it works without expensive and technical sophisticated devices, rendering FISH a cost-effective procedure. The potential for routine application of this method is supported by the availability of commercial test kits for clinically relevant species (e.g. Pseudomonas aeruginosa, B. cepacia) in typical patient specimens such as sputum or blood culture $[24,43]$.

For the detection of $Y$. pestis and Brucella sp., other highly virulent bacterial species potentially misused as bioterrorism agents, similar protocols have successfully been developed $[25,44]$.

The capability to detect and identify the closely related Francisella species within 2-3 hours without expensive preparation of nucleic acids from clinical samples is intriguing and may prove useful considering that misidentification of $F$. tularensis type A as F. tularensis type B and vice versa may occur when identification is based on the immunological detection of the LPS capsule or biochemical tests. In the past, such misidentification led to laboratory infections and resulted in the temporary shutdown of laboratories for cost-intensive decontamination [45]. The sensitivity of the new method is intriguing, since we were able to detect artificial contamination of type $\mathrm{B}$ strains with $F$. tularensis type A as low as $0.1 \%$ of the total bacterial population. Moreover, FISH could prove relevant for the rapid identification of mutations in $16 \mathrm{~S}$ or 23S rRNA gene regions which are associated with or causative for antibiotic resistance of bacterial pathogens against aminoglycosides or macrolides [46].

This investigation showed that Francisella cells infecting different mouse or primate tissues carry sufficient 
numbers of ribosomes to be detected with fluorochrome-labeled oligonucleotides. The probes readily penetrate tissue samples and bacterial cell walls. This technique is well suited to detect the location of a pathogen within the body, an advantage that can be further improved in combination with confocal laser scanning microscopy. This modification could compensate the comparatively low sensitivity of in situ hybridization typically requiring about $10^{5}$ cells per $\mathrm{ml}$ for a positive reaction [25].

"Phylogenetic staining" using fluorescence labeled hybridization probes was employed for several clinically relevant and also environmental bacterial species [27]. For environmental studies, fluorescent in situ hybridization is used for the identification at genus, species and subspecies level especially for uncultivable species making FISH an extremely valuable tool to study ecological niches of bacterial species or symbiotic life styles in complex ecological systems. Future studies will show whether in situ hybridization techniques are sufficiently sensitive to detect dormant or metabolically inactive Francisella cells intracellularly surviving within tissues or in environmental samples like water, soil or arthropod vectors.

\section{Conclusions}

The molecular methods investigated in this study offer alternatives to more traditional diagnostic methods for detection of tularemia in humans and animals. In particular, whole-cell hybridization is a promising, rapid, and cultivation-independent detection method for Francisellae in clinical samples but could also prove useful to detect and explore the newly recognized diversity of Francisella species or Francisella-like organisms in the environment.

Additional file 1: Table S1 and S2. Table S1: PCR primers and probes used in this study (Degenerate oligonucleotides wobble bases according to the IUB code). Table S2: Subspecies specific single nucleotide polymorphisms (SNPS) in the sequence of the $23 \mathrm{~S}$ rRNA gene based on sequences of 29 Francisella strains.

Click here for file

[http://www.biomedcentral.com/content/supplementary/1471-2180-1072-S1.DOC]

\section{Acknowledgements}

The authors would like to acknowledge the excellent technical assistance given by C. Kleinemeier and B. Gramsamer. This work was part of the European biodefence laboratory network (EDA B-0060-ESM4-GC) coordination work on dangerous pathogens.

\section{Author details}

${ }^{1}$ Bundeswehr Institute of Microbiology, German Reference Laboratory for Tularemia, Neuherbergstr 11, 80937 Munich, Germany. ${ }^{2}$ University of Applied Sciences Munich, Lothstr. 34, 80335 Munich, Germany. ${ }^{3}$ Department of Microbiology, Virology \& Hygiene, University Hospital Rostock, Schillingallee 70, 18057 Rostock, Germany.

\section{Authors' contributions}

WDS conceived the study, participated in its design and coordination and drafted the manuscript. ES carried out the molecular genetic studies, analyzed the aligned sequences, constructed phylogenetic trees, participated in the study design and was involved in probe and primer design. EZ performed all hybridization experiments, 235 rRNA gene sequencing, and participated in sequence alignment, probe design and drafting the "methods" part of the manuscript. KT participated in study design, initial sequencing of the five reference strains, development of hybridization protocols and he was responsible for most of the probe design. AP contributed to study design and coordination, helped to draft the manuscript and critically revised its final version. All authors read and approved the final manuscript.

\section{Authors' informations}

WDS and ES direct the German Reference Laboratory for Tularemia, which was repeatedly appointed by the Germany Federal Ministry of Health to provide specialist expertise in the field of tularemia. The predominant task is to give advice and support for special diagnostic problems. The reference laboratory supports physicians, clinical laboratories and public health institutions in diagnosis, treatment and surveillance of tularemia.

Received: 3 September 2009 Accepted: 8 March 2010

Published: 8 March 2010

\section{References}

1. Tärnvik A, Chu MC: New approaches to diagnosis and therapy of tularemia. Ann N Y Acad Sci 2007, 1105:378-404

2. Sjöstedt A: Tularemia: history, epidemiology, pathogen physiology, and clinical manifestations. Ann N Y Acad Sci 2007, 1105:1-29.

3. Whipp MJ, Davis JM, Lum G, de Boer J, Zhou Y, Bearden SW, Petersen JM Chu MC, Hogg G: Characterization of a novicida-like subspecies of Francisella tularensis isolated in Australia. J Med Microbiol 2003, 52:839-842.

4. Leelaporn A, Yongyod S, Limsrivanichakorn S, Yungyuen T, Kiratisin P: Francisella novicida bacteremia, Thailand. Emerg Infect Dis 2008, 14:1935-1937.

5. Keim P, Johansson A, Wagner DM: Molecular epidemiology, evolution, and ecology of Francisella. Ann NY Acad Sci 2007, 1105:30-66.

6. Hopla C: The ecology of tularaemia. Adv Vet Sci Comp Med 1974, 18:25-53.

7. Dennis DT, Inglesby TV, Henderson DA, Bartlett JG, Ascher MS, Eitzen E, Fine AD, Friedlander AM, Hauer J, Layton M, Lillibridge SR, McDade JE, Osterholm MT, OToole T, Parker G, Perl AM, Russell PK, Tonat K: Tularemia as a biological weapon-medical and public health management. JAMA 2000, 285:2763-2773

8. Wenger JD, Hollis DG, Weaver RE, Baker CN, Brown GR, Brenner DJ, Broome CV: Infection caused by Francisella philomiragia (formerly Yersinia philomiragia). A newly recognized human pathogen. Ann Intern Med 1989, 110:888-892.

9. Ottem KF, Nylund A, Karlsbakk E, Friis-Møller A, Kamaishi T: Elevation of Francisella philomiragia subsp. noatunensis Mikalsen et al. (2007) to Francisella noatunensis comb. nov. [syn. Francisella piscicida Ottem et al. (2008) syn. nov.] and characterization of Francisella noatunensis subsp. orientalis subsp. nov., two important fish pathogens. J Appl Microbiol 2009, 106:1231-1243.

10. Mikalsen J, Colquhoun DJ: Francisella asiatica sp. nov. isolated from farmed tilapia (Oreochromis sp.) and elevation of Francisella philomiragia subsp. noatunensis to species rank as Francisella noatunensis comb. nov., sp. nov. Int J Syst Evol Microbiol 2009.

11. Huber BE, Escudero R, Busse HJ, Seibold E, Scholz HC, Anda P, Kämpfer P, Splettstoesser WD: Description of Francisella hispaniensis sp. nov., isolated from human blood, reclassification of Francisella novicida (Larson et al. 1955) Olsufiev et al. 1959 as Francisella tularensis subsp. novicida comb. nov., and emended description of the genus Francisella. Int J Syst Evol Microbiol 2009.

12. Kugeler KJ, Mead PS, Janusz AM, Staples JE, Kubota KA, Chalcraft LG, Petersen JM: Molecular Epidemiology of Francisella tularensis in the United States. Clin Infect Dis 2009, 48:863-870.

13. Barns SM, Grow CC, Okinaka RT, Keim P, Kuske CR: Detection of diverse new Francisella-like bacteria in environmental samples. Appl Environ Microbiol 2005, 71:5494-5500. 
14. Sréter-Lancz Z, Széll Z, Sréter T, Márialigeti K: Detection of a Novel Francisella in Dermacentor reticulatus: A Need for Careful Evaluation of PCR-Based Identification of Francisella tularensis in Eurasian Ticks. Vector Borne Zoonotic Dis 2008.

15. Escudero R, Toledo A, Gil H, Kovácsová K, Rodríguez-Vargas M, Jado I, García-Amil C, Lobo B, Bhide M, Anda P: Molecular method for discrimination between Francisella tularensis and Francisella-like endosymbionts. J Clin Microbiol 2008, 46:3139-3143.

16. Kugeler KJ, Mead PS, McGowan KL, Burnham JM, Hogarty MD, Ruchelli E, Pollard K, Husband B, Conley C, Rivera T, Kelesidis T, Lee WM, Mabey W, Winchell JM, Stang HL, Staples JE, Chalcraft LJ, Petersen JM: Isolation and characterization of a novel Francisella sp. from human cerebrospinal fluid and blood. J Clin Microbiol 2008, 46:2428-2431.

17. Goethert HK, Telford SR: A new Francisella (Beggiatiales: Francisellaceae) inquiline within Dermacentor variabilis say (Acari: Ixodidae). J Med Entomol 2005, 42:502-505.

18. Bernard K, Tessier S, Winstanley J, Chang D, Borczyk A: Early recognition of atypical Francisella tularensis strains lacking a cysteine requirement. $J$ Clin Microbiol 1994, 32:551-553.

19. Petersen JM, Schriefer ME, Carter LG, Zhou Y, Sealy T, Bawiec D, Yockey B, Urich S, Zeidner NS, Avashia S, Kool JL, Buck J, Lindley C, Celeda L, Monteneiri JA, Gage KL, Chu MC: Laboratory analysis of tularemia in wildtrapped, commercially traded prairie dogs, Texas, 2002. Emerg Infect Dis 2004, 10:419-425.

20. Petersen JM, Schriefer ME, Gage KL, Montenieri JA, Carter LG, Stanley M, Chu MC: Methods for enhanced culture recovery of Francisella tularensis. Appl Environ Microbiol 2004, 70:3733-3735.

21. Versage $J$, Severin DD, Chu MC, Petersen JM: Development of a multitarget real-time TaqMan PCR assay for enhanced detection of Francisella tularensis in complex specimens. J Clin Microbiol 2003, 41:5492-5499.

22. Kaysser $\mathrm{P}$, Seibold E, Mätz-Rensing K, Pfeffer M, Essbauer S, Splettstoesser WD: Re-emergence of tularemia in Germany: presence of Francisella tularensis in different rodent species in endemic areas. BMC Infect Dis 2008, 8:157.

23. Petersen JM, Carlson JK, Dietrich G, Eisen RJ, Coombs J, Janusz AM, Summers J, Beard CB, Mead PS: Multiple Francisella tularensis subspecies and clades, tularemia outbreak, Utah. Emerg Infect Dis 2008, 14:1928-1930.

24. Kempf VA, Trebesius K, Autenrieth IB: Fluorescent In situ hybridization allows rapid identification of microorganisms in blood cultures. J Clin Microbiol 2000, 38:830-838

25. Trebesius K, Harmsen D, Rakin A, Schmelz J, Heesemann J: Development of rRNA-targeted PCR and in situ hybridization with fluorescently labelled oligonucleotides for detection of Yersinia species. J Clin Microbiol 1998, 36:2557-2564.

26. Fuchs BM, Syutsubo K, Ludwig W, Amann R: In situ accessibility of Escherichia coli 23S rRNA to fluorescently labelled oligonucleotide probes. Appl Environ Microbiol 2001, 67:961-968.

27. Amann Rl, Krumholz L, Stahl DA: Fluorescent-oligonucleotide probing of whole cells for determinative, phylogenetic, and environmental studies in microbiology. J Bacteriol 1990, 172:762-770.

28. Lane DJ: 16S/23S rRNA sequencing. Nucleic acid techniques in bacterial systematics John Wiley \& Sons, Inc., New York, N.YStackebrandt E, Goodfellow M 1991, 115-175.

29. Amann RI, Binder BJ, Olson RJ, Chisholm SW, Devereux R, Stahl DA: Combination of $16 \mathrm{~S}$ rRNA-targeted oligonucleotide probes with flow cytometry for analysing mixed microbial populations. Appl Environ Microbiol 1990, 56:1919-1925.

30. Lathe R: Synthetic oligonucleotide probes deduced from amino acid sequence data. Theoretical and practical considerations. J Mol Biol 1985, 183:11-12

31. Lutter D, Langmann T, Ugocsai $P$, Seibold E, Splettstoesser WD, Gruber $P$, Lang EW, Schmitz G: Analyzing time-dependent microarray data using independent component analysis derived from expression modes from human macrophages infected with $F$. tularensis holarctica. J Biomed Inform 2009, doi:10.1016/j.jbi.2009.01.002.

32. Forsman M, Sandström G, Sjöstedt A: Analysis of $16 \mathrm{~S}$ ribosomal DNA sequences of Francisella strains and utilization for determination of the phylogeny of the genus and for identification of strains by PCR. Int J Syst Bacteriol 1994, 44:38-46.
33. Splettstoesser WD, Piechotowski I, Buckendahl A, Frangoulidis D, Kaysser P, Kratzer W, Kimmig P, Seibold E, Brockmann SO: Tularemia in Germany: the tip of the iceberg?. Epidemiol Infect 2009, 137:736-743.

34. Martín C, Gallardo MT, Mateos L, Vián E, García MJ, Ramos J, Berjón AC, del Carmen Viña M, García MP, Yáñez J, González LC, Muñoz T, Allue M, Andrés C, Ruiz C, Castrodeza J: Outbreak of tularaemia in Castilla y León, Spain. Euro Surveill 2007, 12(11):E0711081.1.

35. Akalin H, Helvaci S, Gedikoglu S: Re-emergence of tularemia in Turkey. Int J Infect Dis 2009, 13:547-551.

36. Splettstoesser WD, Tomaso H, Al Dahouk S, Neubauer H, Schuff-Werner P: Diagnostic procedures in tularaemia with special focus on molecular and immunological techniques. J Vet Med B Infect Dis Vet Public Health 2005, 52:249-261.

37. Bauernfeind A, Roller C, Meyer D, Jungwirth R, Schneider I: Molecular procedure for rapid detection of Burkholderia mallei and Burkholderia pseudomallei. J Clin Microbiol 1998, 36:2737-2741.

38. Antonov VA, Tkachenko GA, Altukhova W, Savchenko SS, Zinchenko OV Viktorov DV, Zamaraev VS, llyukhin VI, Alekseev W: Molecular identification and typing of Burkholderia pseudomallei and Burkholderia mallei: when is enough enough?. Trans $R$ Soc Trop Med Hyg 2008, 102(Suppl 1): S134-139.

39. Nübel $U$, Reissbrodt $R$, Weller $A$, Grunow R, Porsch-Ozcürümez $M$, Tomaso H, Hofer E, Splettstoesser W, Finke EJ, Tschäpe H, Witte W: Population structure of Francisella tularensis. J Bacteriol 2006, 188:5319-5324

40. Broekhuijsen M, Larsson P, Johansson A, Byström M, Eriksson U, Larsson E, Prior RG, Sjöstedt A, Titball RW, Forsman M: Genome-wide DNA microarray analysis of Francisella tularensis strains demonstrates extensive genetic conservation within the species but identifies regions that are unique to the highly virulent F. tularensis subsp. tularensis. J Clin Microbiol 2003, 41:2924-2931.

41. Tomaso H, Scholz HC, Neubauer H, Al Dahouk S, Seibold E, Landt O, Forsman M, Splettstoesser WD: Real-time PCR using hybridization probes for the rapid and specific identification of Francisella tularensis subspecies tularensis. Mol Cell Probes 2007, 21:12-16.

42. Kugeler KJ, Pappert R, Zhou Y, Petersen JM: Real-time PCR for Francisella tularensis types A and B. Emerg Infect Dis 2006, 12:1799-1801.

43. Brown AR, Govan JR: Assessment of fluorescent in situ hybridization and PCR-based methods for rapid identification of Burkholderia cepacia complex organisms directly from sputum samples. J Clin Microbiol 2007, 45:1920-1926.

44. Wellinghausen N, Nöckler K, Sigge A, Bartel M, Essig A, Poppert S: Rapid detection of Brucella spp. in blood cultures by fluorescence in situ hybridization. J Clin Microbiol 2006, 44:1828-1830.

45. Lawler A: Biodefense labs. Boston University Under Fire for Pathogen Mishap. Science 2005, 307(5709):501.

46. Trebesius K, Panthel K, Strobel S, Vogt K, Faller G, Kirchner T, Kist M, Heesemann J, Haas R: Rapid and specific detection of Helicobacter pylori macrolide resistance in gastric tissue by fluorescent in situ hybridisation. Gut 2000, 46:608-614.

doi:10.1186/1471-2180-10-72

Cite this article as: Splettstoesser et al.: Rapid differentiation of

Francisella species and subspecies by fluorescent in situ hybridization targeting the $23 \mathrm{~S}$ rRNA. BMC Microbiology 2010 10:72.

\section{Submit your next manuscript to BioMed Central and take full advantage of:}

- Convenient online submission

- Thorough peer review

- No space constraints or color figure charges

- Immediate publication on acceptance

- Inclusion in PubMed, CAS, Scopus and Google Scholar

- Research which is freely available for redistribution

Submit your manuscript at www.biomedcentral com/submit
C Biomed Central 